\title{
Mapping the relationship between international sport and diplomacy
}

\author{
Stuart Murray $^{\mathrm{a}}$ and Geoffrey Allen Pigman ${ }^{\mathrm{b} *}$ \\ ${ }^{a}$ Faculty of Humanities and Social Sciences, Bond University, Gold Coast, Australia; ${ }^{b}$ Department \\ of Political Sciences, University of Pretoria, Pretoria, South Africa \\ ${ }^{*}$ Corresponding author. Email: gapigman@mindspring.com
}

To date, the relationship between diplomacy and international sport has been relatively undertheorized. This paper seeks to redress the deficiency by proposing an analytical taxonomy of the multiple convergences between international sport and diplomacy. The principal analytical distinction to be drawn is between (1) international sport consciously employed by governments as an instrument of diplomacy and (2) international-sport-as-diplomacy, the diplomatic representation, communication and negotiation between non-state actors that take place as a result of ongoing international sporting competition. By increasing understanding of the ro^les of sport in diplomacy and diplomacy in sport, the paper seeks to promote the adoption of best practices to facilitate effective use of sport in diplomacy by governments and effective use of diplomacy by international sporting bodies, and to instigate a debate between theorists and practitioners from both realms.

\section{Introduction}

For millennia, there has been an association between sport and politics. When sport provides a function beyond the 'game', it is often embraced by ruling elites. The Ancient Olympiad, for example, begun in $776 \mathrm{BC}$ 'in a religious setting as one of the activities during the festival of Zeus', subsequently morphed into a sporting-competition, a gift to the people and a way to sublimate conflict, and was abolished in 394 AD by the Roman Emperor Theodosius I as part of the campaign to abolish Paganism and impose Christianity as a state religion (Hugh 1998). In the nineteenth century, the strategic rivalry between Britain and Russia for supremacy in Central Asia was considered the 'Great Game' (or 'Tournament of Shadows'). For the British, spurred on by Henry Newbolt's Vitai Lampada, a stirring homage to sport and war, sport was one of the foundations on which empire was spread and consolidated. And more recently, the twentieth century has seen a relationship between sport and fascism, apartheid and racism, as well as myriad partnerships that fall under the broad heading of sport and development. Much has been written on these and other topics.

Notwithstanding the long-running relationship between sport and international politics, far less scholarship has been undertaken on the means and instrumentalities for enacting the relationship: diplomacy. In the theory and practice of diplomacy, the relationship between international sport and diplomacy is a familiar but relatively underexplored area. Beyond a collection of anecdotal, sporadic and case-specific articles on ping-pong, baseball and football diplomacy, no meta-review of the theory and empirical data relating to 'sports-diplomacy' has occurred. This is a deficiency that this paper seeks to redress. 
In analysing the multifold networks, actors and channels where international sport and diplomacy converge two distinct categories of sports diplomacy emerge. The first is comprised of cases in which international sport is consciously employed by governments as an instrument of diplomacy. The second category - international-sport-as-diplomacy concerns the diplomatic representation, communication and negotiation between non-state actors that take place as a result of ongoing international sporting competition.

The former category, in which sport is employed by governments as an instrument of diplomacy, is the more familiar form of sports diplomacy. In this traditional sense where diplomacy is the 'dialogue between states', sports diplomacy is often associated with governments employing sportspeople to amplify a diplomatic message, or with states exploiting sporting events for public diplomacy opportunities, to cool tensions in flagging diplomatic relationships or to simply test the ground for a possible policy change.

The latter category, international-sport-as-diplomacy, is less well understood. It includes the effects of both international sport on diplomacy and the specialized diplomacy of international sport: the diplomatic activities that occur to make international sporting competition possible. In the modern, plural diplomatic environment, non-state actors such as the International Olympic Committee (IOC) and the Fédération Internationale de Football Association (FIFA) can be said to practice a distinct type of diplomacy. These organizations and individuals consistently engage in representation to and negotiation with governments, the regional and national organizing bodies of sport, large global firms that sponsor competition, global media firms and global civil society organizations (CSOs). Arguably, the impact of this category on diplomacy is greater by virtue of its volume, frequency and ability to engage the hearts, minds and wallets of the global public.

Of these two categories of sports diplomacy, the first is much smaller than the second, as most international sport is organized for purposes officially unrelated to diplomacy. The traditional and non-traditional types of sports diplomacy overlap on important occasions, as in the creation of the ancient Olympiad expressly for purposes of promoting peace and comity and sporting excellence. Yet, at the same time, each raises a distinct set of analytical and normative questions that are long overdue to be addressed. Considering the recent interest in sports as a soft power tool, the timing for a systematic investigation of sports diplomacy is ideal.

This paper aims to establish, critique and evidence both categories. Its purpose is to map the theoretical and practical terrain of sports diplomacy and to frame a number of debates conducive to a regular discussion with theorists and practitioners from both realms. The paper begins by exploring sport as an instrument of diplomacy and then goes on to investigate international-sport-as-diplomacy, introducing and substantiating a unique form of non-traditional diplomacy: the specialized diplomacy of international sport.

\section{International sport as a diplomatic instrument}

In a traditional sense, diplomacy is 'the conduct of relations between sovereign states with standing in world politics by official agents and by peaceful means' (Bull 1977, 156). ${ }^{1}$ Where foreign policy concerns a state's ends, diplomacy is the means to those ends. Diplomacy is the 'engine room' (Cohen 1998, 1) of international relations and the 'masterinstitution of international society' (Wight and Butterfield 1966, 10-12). The scope of traditional diplomacy is vast. In addition to negotiation, communication, information gathering and dissemination, representation and the minimization of friction in international affairs, traditional diplomacy is not averse to employing unconventional 
means, partners and avenues to amplify its message. On occasion, cultural exchanges such as the 2008 visit to North Korea by the New York Philharmonic can substitute for more formal diplomatic interaction, or soft power institutions like the Goethe Institute or the British Council can create new channels for diplomacy. Sport is no different.

Etymologically speaking, the origins of the English word 'sport' lie in the French word desport, roughly translated as leisure. And for Kyle (1983):

... 'sport' is a non-ancient and vague term at best. 'Athletics' usually suggests competition, training, prizes and the goal of victory. 'Physical education' implies instruction and the exercise of the body. 'Recreation' or 'leisure' applies to non-work, relaxation and rejuvenation with pleasure or fun as a goal. 'Sport' is used as a general rubric for all these areas as well as hunting, dance and even board games (278).

Sport is a complex phenomenon; however, this section of the paper focuses on international sport, whose essence - from the Hellenes through to the present - is unmistakable: being the best you can be, the pursuit of sporting excellence and preferably - winning.

Sport, politics and diplomacy have long been compatible. When sport provides a useful function, it is usually 'co-opted by politics' (Jackson and Haigh 2008). International sport creates opportunities for governments to demonstrate various types of superiority, from their athletic prowess to the ideology of a particular system of state. Governments are well aware of the power of the opiate of the masses and have long been drawn towards sport and sporting festivals. As Allison $(1993,17)$ notes, all kinds of governments:

have endorsed international sporting competition as a testing ground for the nation or for a political 'system'. German Nazis, Italian Fascists, Soviet and Cuban Communists, Chinese Maoists, western capitalist democrats, Latin American juntas - all have played the game and believed in it.

The mixing of sport, diplomacy and politics is part of the milieu of international relations. Sports diplomacy - a theoretical and practical hybrid of two significant institutions - is the specialization, exploitation and reification of a familiar aspect of state-qua-state interaction.

In the contemporary diplomatic environment, conditions are ideal for sports diplomacy. The appearance of 'new' diplomatic actors - CSOs, multinational corporations $^{2}$ and intergovernmental organizations, and even influential celebrities -has consolidated expressions like plural, 'polylateral' (Wiseman 1999) or 'multistakeholder' (Hocking 2006) to describe the vertical and horizontal networks that characterize modern diplomacy. In this dynamic environment, international sportspeople can be employed to augment a foreign policy message; rancorous diplomatic relationships can be bridged through sport or, as was the case with the ban placed on apartheid South Africa, sport can be used as a punitive tool. A nation can also express its disdain by simply saying 'we're not playing', as was the case when the USA boycotted the 1980 Moscow Olympics, a gesture reciprocated by the Soviet Union and 13 satellite states when they refused to participate in the 1984 Los Angeles Olympic Games. Clearly, sports diplomacy plays a major part in the international life of governments.

There is a long history of sporting competition being used in diplomacy as a device to mediate estrangement, in Der Derian's (1987) terminology, between peoples, nations and governments. Such mediation can extend from the sublimation or controlled release of hostility to the avoidance or management of conflict. The ancient Olympiad, an athletic and religious festival that ran every four years uninterrupted from $776 \mathrm{BC}$ to $393 \mathrm{AD}$, for example, initiated the idea of a Truce during competition. Travelling fans were afforded 
protection, and the Truce 'forbade all states participating in the games to take up arms, to pursue legal disputes or to exercise death penalties' while the Games took place (Scrambler 2005, 15 ).

Or, sport between nations and people can be used to consolidate political developments, as was the case with the 1520 meeting between King François I of France and Henry VIII of England. The summit at the Fields of Cloth of Gold in northern France, where the two kings and their retinues wrestled, jousted and competed in archery events over a period of two weeks, was arranged to strengthen the bond of friendship between the two monarchs after the Anglo-French treaty of 1514 (Mattingly 1938). The majority of these pre-Westphalian contests were consciously organized by polities for the purpose of reducing tension and as a means for alienated peoples to view each other as sharing interests and humanity through sport.

In the modern era, sports diplomacy can be instigated by non-governmental organizations or competitors and then embraced by government officials for their potential value as a diplomatic mission. The most famous example of this is the April 1971 visit by the US Table Tennis team to China. This historic visit was first proposed by the US notfor-profit National Committee on USA-China relations after an opportune meeting between the flamboyant American player Glenn Cowan and the three-time Chinese world champion Zhuang Zedong at the 31st World Table Tennis Championship in Nagoya, Japan, in March 1971 (Huang 2008). ${ }^{3}$ The proposal was then embraced by the Mao and Nixon governments as a vehicle to test whether the public of the two countries would be accepting of a more formal diplomatic opening of frozen relations between the two cold war adversaries. Ping-Pong diplomacy paved the way for US National Security Adviser Henry Kissinger's July 1971 visit and the more famous visit by US President Richard Nixon in February 1972.

Sports diplomacy can also create alternate channels for diplomacy, allowing states to move beyond entrenched foreign policy positions. The episodic cricket diplomacy between India and Pakistan, for example, demonstrates that the two nations and peoples share a common interest in/through sport despite decades of bitterness. After the Kashmir crisis of 2002 left the two nations on the brink of war, a series of cricket matches were facilitated by both governments in 2004 to reduce tensions and explore the possibility of normalizing relations, opening borders and resuming direct security negotiations.

Similarly, after the 2008 Mumbai terrorist attacks froze relations, cricket was once more employed as a diplomatic tool. In 2011, Pakistani Prime Minister Gilani accepted an invitation from his Indian counterpart Manmohan Singh to attend the Cricket World Cup semi-final match between the South Asian rivals in Mohali, India. The occasion was touted as 'an attempt to use sport to create a feel-good atmosphere between the two countries at a time when the atmosphere of suspicion and hostility towards Pakistan in India is very strong' (Rupert 2011). The Singh-Gilani meeting was followed by an assembly of foreign secretaries in mid-2011 and, once more, a slow normalization of relations.

Whether it is baseball diplomacy between the USA and Cuba or football diplomacy between Turkey and Armenia, sport can be a powerful diplomatic tool. Sports diplomacy transcends cultural differences, provides different avenues for increased dialogue and unites disparate peoples through a mutual affection for sport. More specifically, sports diplomacy involves representative and diplomatic activities undertaken by sportspeople on behalf of and in conjunction with their governments. The practice is facilitated by traditional diplomacy and uses sportspeople and sporting events to engage, inform and create a favourable image among foreign publics and organizations, to shape their perceptions in a way that is (more) conducive to the sending government's foreign policy 
goals. ${ }^{4}$ While traditional diplomacy is the means to a state's foreign policy ends, sports diplomacy is one of the means to the means of those ends.

In modern diplomacy, there are four obvious benefits for governments using sport as an instrument of diplomacy. First, radical changes in the modern diplomatic environment have forced traditional diplomatic institutions to reform, adapt and experiment. Sports diplomacy embodies a proactive government response to the common argument that diplomacy is irrelevant, obsolete, 'dead' (Ramsay 2006) 'fossilized' (Modelski 1972) and in a general state of deliquescence. By employing sports, the image of a state's diplomacy can change from aloof, hermetic and irrelevant to one that is innovative, effective and public (and even fun). Moreover, in the postmodern information age, foreign publics are more likely to be engaged by soft power overtures from nations, such as cultural or sporting exchanges. Today sport and diplomacy are no longer niche or backwater institutions but powerful foreign policy tools when working in tandem.

Second, sport and sportspeople can amplify a state's diplomacy. The US Department of State, for example, typifies a rallying call 'to aggressively use sports as a diplomatic tool' through programmes like their SportsUnited initiative. ${ }^{5}$ After $9 / 11$, State used sport as a way to engage young Muslims across Africa, the Middle East and South Asia - a demographic that had previously been difficult to reach. As Walters (2007) notes of the reasons behind this innovation:

Only certain cultures or segments of society show strong interest in speaking English, travelling to the United States, attending a classical music event, or participating in a discussion on human rights. On the other hand, virtually all cultures and all citizens have an interest in and appreciation for sport. This makes it one of the best methods for exchange especially for diplomats operating in an age when the opinions of foreign publics are so crucial for success.

Today, the Department of State regularly employs 'Sports Envoys' such as figure skater Michelle Kwan and baseball star Cal Ripken Jr to engage in sports diplomacy. Since 1961, the German Federal Foreign Ministry has used sport as a 'peace policy instrument' in developing countries and crisis areas, to 'break down prejudice, [and to] strengthen minorities' (Auswärtiges Amt 2010). And similarly, the Japanese Ministry of Foreign Affairs (MOFA) regularly exploits and mobilizes football and footballers. Football is used to overcome imperial stereotypes and one intention behind the formation of the J-league in the 1990 s, for example, was to improve the performance of the national team to reflect 'a level worthy of its [Japan's] economic power and overall achievements after 40 years of post-war peace and prosperity' (Manzenreiter 2008). In the twenty-first century, MOFA has employed football to 'secure a peaceful environment for Japanese troops in Iraq', to bridge divides between Balkan states and frequently invites 'Israeli and Palestinian youth players to participate in training camps in Japan' as a way of getting to know the 'other' (Manzenreiter 2008, 421-423).

In these respects, sport has a transcendental quality, and governments are keen to tap in. After all, nobody is opposed to sports; it has a global, universal quality: 'who is against sport? No one, or almost no one. The Inuits are as interested in the World Cup as the Argentineans, Congolese and Europeans' (Redeker 2008). Where the USA, Germans and Japanese lead, other nations will follow. Sports-diplomacy exchanges promote international understanding and friendship, as well as dispel stereotypes and prejudices. Not to mention, they are also 'low-risk, low-cost and high profile' (Keech and Houlihan 1999).

Third, sporting mega-events can offer significant public diplomacy opportunities. Approximately 3.9 billion people watched the 2004 Athens Olympics, while a staggering 
1 billion people, or $15 \%$ of the global population, tuned in for the 2008 Beijing Olympics opening ceremony (Jackson and Haigh 2008). To stage a mega-event is confirmation that the host nation is a good international citizen and if the diplomatic posture, image and message is thoughtfully crafted and aligned to positive sporting values, the perception of a foreign public can be significantly altered. Beijing's 2008 'coming out' party where they used the Olympic Games to foster and consolidate an image of China as a rising, modern, economic powerhouse is a sound example. Using sport, it is likely that Brazil will proselytize an image of a South American regional leader and powerhouse on the back of the 2014 Football World Cup and 2016 Olympic Games.

A fourth reason for government using international sport as a diplomatic tool concerns the compatibility of the two institutions. Diplomacy represents the business of peace and is a physical manifestation of international society, civility and order within an anarchic environment. Similarly, sport is a pacific means of international exchange short of open conflict. When Butterfield writes that 'diplomacy may include anything short of actual war, therefore, and sometimes the kindest thing that one can say of it is that it is better than having the guns actually firing' (Jackson and Haigh 2008, 351), the same can be said of sporting encounters. Sport can sublimate conflict by conducting the metaphorical battle in the stadia. In Orwell's famous remark, sport, like diplomacy, is 'war, minus the shooting'.

The diplomats and sportspeople also share certain commonalties. Both characterize an elite stratum of society, and, while the former may do it more graciously than the latter, ${ }^{6}$ both represent their country in the international arena. Just as sportspeople vie with one another, diplomats also compete in a great game that involves rules, tactics and opponents. In both vocations mediocrity of performance is disparaged while winning and success are rewarded with progress, increasing recognition and the ability to compete against the best in the world. And just as diplomats are prized for their 'open, genial and civil ${ }^{7}$ manner, the same qualities are evident in successful sports diplomats, such as the part-time Chinese envoys Yao Ming (basketball) and Liu Xiang (hurdling). Superstar footballers like Lionel Messi or Didier Drogba have more in common with superstar diplomats like Chris Patten or Gareth Evans than first impressions suggest.

Considering these four beneficial collusions between sport and diplomacy, the potential for sports diplomacy is promising. Speaking on the topic at the Second Hague Conference on Diplomacy in 2009, former US Ambassador to Denmark, H.E. Jim Cain (2009), said as much:

Sports can be a powerful medium to reach out and build relationships ... across cultural and ethnic divides, with a positive message of shared values: values such as mutual respect, tolerance, compassion, discipline, equality of opportunity and the rule of law. In many ways, sports can be a more effective foreign policy resource than the carrot or the stick.

In the twenty-first century, the potential for sports diplomacy is vast. However, governments the world over should be aware of a number of theoretical and practical anomalies that result from 'mixing' sport with diplomacy. If a more permanent, proactive form of sports diplomacy is desirable, an awareness of these issues is important.

Moving beyond the idealistic rhetoric, sports diplomacy can seem an odd hybrid, particularly from the perspective of a global sporting public. While the two cultures share certain similarities, the differences may be more significant and allude to the reason why, to date, sports diplomacy has been limited, anecdotal and sporadic. As Defrance and Chamot (2008) suggest:

the two cultures - sporting and diplomatic - are poles apart ... . in the former, agents express themselves through their body, in the latter, they work with words: while the former 
show themselves, the latter act with discretion: the rise of 'adrenalin' among sportsmen differs from the quiet gestures of diplomats, the clamour of the stadium is the opposite of the peaceful atmosphere of embassies (395).

Traditional diplomacy takes place behind closed doors, far away from the 'clamour', the public and media scrutiny. It occurs in a civilized, orchestrated and cloistered environment where outcomes are often decided or expected beforehand. On the other hand, sport is very public, unpredictable, fluid and, at times, highly uncivilized. The outcome is rarely known before the meeting takes place and sporting encounters are open to greater scrutiny.

There are other significant differences in the two cultures. In diplomacy, while there are winners and losers, winning is not everything. After all, the business of successful negotiation is 'to get what you want, while helping the others get what they want', to create positive win-win situations and, where possible, to build mutually beneficial partnerships conducive to national and collective interests. Conversely, a popular view of sport holds that winning is everything. While sports diplomacy promotes catchphrases like 'it's not the winning, it's the taking part that counts', sport is built on Lombardisms like 'winning isn't everything - it's the only thing'. Sports fans do not watch the accoutrements of sport - their heroes training, or the arrival of the dignitaries at the stadium: they watch heated battles imbued with national fervour. For the majority of the direct participants in international sports - the fans, the players, and the managerial and administrative staff the essence of sport is not only built representing one's country to the best of one's abilities, but it is also built on fierce zero-sum competition: winning, in other words.

Moreover, in the present, as in the past, sport is associated with suffering and war - the antithesis of diplomacy (Sweet 1987). ${ }^{8}$ Sport is universally saturated with references to war, battle and tribalism. For Fischer, sport 'imitates' war, 'a sampling of the daily sports page reveals conquest, battle, war, destruction, victory ... the taking of manhood, honour and prestige' (Fischer 2002, 16), hardly the sort of values that sports diplomacy champions. Virtues, values and 'humanitarian gestures', Redeker writes, 'have no place in sports' in that they 'blatantly contradict sportive logic' (2008, 497-498). For the advocates of sports diplomacy, there appears to be a naive gap between sporting reality and sporting idealism. Besides the aspirational values sport can demonstrate, there is a darker, Hobbesian aspect to sport.

In international sports, sports fans become emotionally involved with their national team - and the anthems, mass shows of patriotism and symbolism certainly heighten the sense of nationalism. For example, during the 2004 Asian Football Cup, hosted by China, Japan's national side faced hostility everywhere they played. Chinese spectators heckled the players, sang anti-Japanese songs from the war of liberation and 'displayed banners reading "Look into history and apologize to the Asian People", or "Return the Diaoyu (Senkaku) Islands!"' (Manzenreiter 2008, 423). In this respect, sport contradicts diplomacy, whose core function is the minimization of friction in international affairs. Therefore, the idea of using sport as a means of bringing estranged nations closer together can seem far-fetched. Heralding sports diplomacy as a soft and fluffy panacea to the growing pains of globalization is problematic simply because it is not true. International competition can exaggerate animosity, becoming a prelude to hostility and, in the worst case, violence.

Whether it is riots, war or terrorism, sport has a long association with violence. Recalcitrant state and non-state actors can - similarly - use sport to publicize their grievances, to spread fear or to distribute a message to a vast global audience. For example, a week after the 1972 Munich Games tragedy, where 11 Israeli athletes were kidnapped and murdered by Black September, a radical Palestinian organization, the group issued the following communique: 
A bomb in the White House, a mine in the Vatican, the death of Mao-Tse-tung, an earthquake in Paris could not have echoed through the consciousness of every man in the world like the operation at Munich ... the choice of the Olympics, from a purely propagandistic viewpoint was 100 percent successful. It was like painting the name of Palestine on a mountain that can be seen from the four corners of the earth (Toohey 2008, 434).

Between 1972 and 2005, '171 sport-related terrorist attacks have been logged' (Jackson and Haigh 2008, 351). These numbers confirm a negative aspect of sports diplomacy: just as sport can disseminate positive sporting values, there is a 'strong underlying connection' between sport and the publication of undiplomatic messages (Toohey 2008, 429). Writing on the attraction of soccer to terrorists, for example, Kuper $(2010,293)$ notes that:

the main allure of soccer to terrorists is the game's global reach. Terrorism is a form of public relations. The aim is to spread as the greatest fear with the least effort. To do that, terrorist seek out the most public places and events. That means sport.

Animosity, war and violence are manifest in sport. Therefore, when a Department of State official says that 'sports-diplomacy is not really about competition at all. It is about respect for diversity, leadership, teamwork and dialogue', it can sound rather idealistic (Walters 2007). The reality of sport produces cheaters, hand-ballers, head-butters, rapists, dogfighters, dopers, match-fixers and gamblers, a host of nasty characters and elements that are distinctly anti-diplomatic in their nature, attitude and profession. This gap between sporting reality and sporting idealism is counterproductive for sports diplomacy, because it affects the credibility of the messenger, which means the message - no matter how positive - can fall on deaf ears. As Redeker notes, 'countries think they are using sports for their own purposes, for the furthering of some political strategy, when in reality ... people pick up just the opposite message their states think they are sending' $(2008,495)$. Words and messages that have some meaning in international relations are nothing more than 'empty sounds .. . after passing through the gates of sport' (Redeker 2008, 498). Where sports diplomacy is concerned, there is also a disconnect between competitors used as national representatives and the bulk of their fellow sportsmen and women. Those chosen to become sports envoys embody the aspirational version of sport that governments imagine and are thus unrepresentative of 'real' sport. A David Beckham - handsome, squeaky clean, marketable and a hero - is preferable over a Wayne Rooney, who has demonstrated an utter lack of diplomacy on and off the pitch.

In terms of diplomats or government officials impinging on sport, they can be regarded with suspicion by the discerning sports fan. The reason is that for some sport is sacrosanct. Set free by globalization, sport has a 'spiritual power' (Redeker 2008, 499) and exists in hallowed realms, 'above' government (Allison 1993, 5). For these puritans, sport is something magical, an 'ideal not to be tainted by the corrupt and divisive elements of society' (Allison 1993, 5-6). When governments and their diplomats encroach into this realm - talking up sport as a diplomatic tool, exploiting sport as a means to an end - could suggest that they see sport as 'below' them: 'a trivial diversion from any serious human purpose, pursued by "muddied oafs on flannelled fools" in Kipling's famous phrase' (Allison 1993, 5-6). For the sporting public, politics 'remain ignorant of the true nature of sport', (Redeker 2008, 499) and confusing sport-as-a-tool for political or diplomatic purposes with sport-as-sacred can be interpreted as sacrilegious and disrespectful. For many, sport is neither 'above' nor 'below' governments - it is beyond them and there it should be left, pure, untouched and untapped. 9

Furthermore, the 'suits' that congregate at grand sporting occasions are the diplomatsin-chief: heads of state that ghost in to toss the coin, declare the 'games to begin' or present the trophy. For the critics of sports diplomacy, a head of state's interest in sport is nothing 
more than a sham, a gimmick or a photo-op, a politician pretending to have a common interest with their subjects to secure a few votes. Positive experiences, such as Nelson Mandela's appearance at the final of the 1995 Rugby World Cup final, are the exception rather than the rule. Just ask any Australian cricket fan how they felt about former Prime Minister John Howard's woeful bowling performance while visiting Pakistan in 2008. Failing to land a ball remotely near the wicket, the PM embarrassed Australia and its proud sporting pedigree immeasurably (Farr 2010).

Sports diplomacy, in this respect, generates the sort of criticism that summit diplomacy attracts. For example, that 'carefully orchestrated meetings' between powerful political figures constitute nothing more than 'dramatic theatre' with a sporting backdrop (Constantinou 1996, 95-97). Add to the sports-diplomacy venues, 'the power of television and sprinkle the surface with exotic locations of great symbolic significance', and sports diplomacy becomes 'an irresistible dish' ${ }^{10}$ for statesmen (Berridge 2002, 173). Backslapping and high-fiving heads of state pretending to like sport for political opportunities are not a good image for sports diplomacy. Respecting the boundaries between sport and diplomacy is crucial to weaving a durable relationship.

If traditional diplomatic actors wish to unleash the potential of sports diplomacy, an awareness of the above-mentioned issues is important. In the modern diplomatic environment, perhaps the time has come to utilize positively the soft power benefits of sport and diplomacy. For those involved, a new perception is offered to challenge entrenched social constructions of the 'other'. Sport can transcend borders, security rivalries and break the ice over nuclear stand-offs. Through sport, an opportunity can present itself to translate dangerous relations into acceptable, friendly and competitive rivalry. The 'low' political agenda - campaigns for sustainable development, worldwide literacy or human security, for example - can be thrust into the global sporting conscience if a Beckham or a Griffey offers their substantial representative clout. With further research and showing due respect for both the sacrosanct and uglier side of sport, sports diplomacy does have significant potential to be an effective tool in the toolbox of twentyfirst-century diplomats.

\section{International-sport-as-diplomacy: mapping the relationship}

The nature of the second broad type of sports diplomacy, international-sport-asdiplomacy, is less transparent and more elusive than the first. What we think of today as international sport, competition that takes place between competitors representing different political jurisdictions or entities, has existed since ancient times. It has evolved in large part out of the quest for excellence that inheres in every game or sporting pursuit. To be the best, or even to play at the highest standard, and to be seen by others who know the sport as performing at that level, of necessity involves competing against the best in the world. By the nineteenth century, sport as a leisure activity had spread to the emerging middle-class population, first in Europe and thenceforth over the rest of the globe. One result of this democratization of sport was that competitors and fans alike began to demand elite competition that could produce competitors recognized as 'best' on a global scale. The founding of the modern Olympics by Baron de Coubertin in 1896 and the establishment of the World Cup of association football/soccer in the early twentieth century are emblematic of this process (Sugden and Tomlinson 1998). Hence, the forms and processes of international sporting competition are internal to the norms and excellences of each sport as recognized by participants and followers of the sport. 
In contrast to sporting competition undertaken specifically as an instrument of diplomacy, the vast majority of international sport is not undertaken for any diplomatic purpose at all. Chehabi (2001) characterizes this sort of competition as a form of peopleto-people 'intersocietal relations', distinct from interactions between governments or transnational CSOs. Yet although most international sporting competition is not an intentional form of diplomatic instrument used by governments, international sport nonetheless serves as a form of diplomacy in its own right. Like more traditional diplomacy between governments, international sporting competition mediates estrangement between states, peoples and other actors. Like sending and receiving embassies, negotiating agreements and resolving conflicts, the activity of international sport is fundamentally that of representation and communication. Like other forms of diplomacy, international sport takes place in identifiable stages and venues. As such, the impact of international sport-for-its-own-sake upon the ongoing diplomatic relationships between governments, peoples and other actors can be broken down into two major categories, each of which warrants study as a significant component of contemporary diplomacy in its broadest sense. First, international sport as it is practiced has direct effects upon diplomatic relations between governments, nations and peoples continually and in a range of ways. Second, the practice of international sport necessitates a whole category of multi-actor, specialized diplomacy that is required to make international sporting competition possible.

\section{Effects of international sport on diplomacy}

Sporting competition between competitors or teams representing nations has a wide range of effects upon diplomacy. The most famous and enduring diplomatic effect of international sport is to suspend, defer or sublimate conflict between polities. The primary purpose of the Olympic Truce, both ancient and modern, has been to suspend warfare or violence over the period of Olympic competition to enable competitors and spectators to leave their military positions (when required) and travel to the site of competition (International Olympic Truce Centre 2012). The Olympic Truce has always been aspirational, in that compliance through history has been far from complete. Yet like other international norms and canons of international law, it is probably better judged by what it is likely to have accomplished in terms of averting conflict that otherwise would have taken place rather than by what it has failed to achieve. The Olympic Truce failed to prevent Russia's invasion of the Georgian Republic during the 2008 Beijing Olympiad. But objectionable though it was, the invasion did not ruin the Games or discourage the global public from supporting the Olympic 'movement'.

Widespread global public interest, support and viewership are crucial to the success of international-sport-as-diplomacy. Large international sporting events have a huge public diplomacy impact upon the global public viewing the event either in person or through the media. The public see the assembled nations of the world, represented by their respective competitors, coming together in one place to engage in an organized, safe and non-violent competition, and they take away the impression that international cooperation is both possible and positive. Competitors represent their nations and their peoples in a real sense, even though they have not been appointed by their national governments to do so. Competitors share with their counterparts from other states a commitment to excellence, respect for the rules and a love of the game. Hence they form a distinct type of community that is a particular microcosm of the world at large, much as the corps diplomatique in each capital city is a representative microcosm of the global community with shared 
values alongside each member's commitment to represent his or her state as best as possible (Leira and Neumann 2008).

An effect of international sport upon diplomatic relations at the other extreme is to heighten national tensions and exacerbate troubled relationships. In one of the worst such incidents, conflict between fans of El Salvador and Honduras at three bitterly contested qualifying football/soccer matches in July 1969 for the FIFA 1970 World Cup was used as a pretext for war between the two nations. Following the Soviet invasion of Czechoslovakia in August 1968, ice hockey and water polo competitions between the two national sides were marred by violence (Chehabi 2001). Hence the preparations for international sporting events require diplomatic cooperation between teams, governing bodies of sport and governments to make competitions secure for competitors, spectators and service providers around the venue. ${ }^{11}$ For example, on a regular basis, football/soccer matches must be played in empty stadiums owing to hostility between rival groups of fans, often at club level, but occasionally at the international level as well. Fans are monitored during matches and arrested for articulating expressions of racism and homophobia. Security preparations for major regional and international competitions, particularly in football/soccer, routinely include the sharing of information to exclude known 'hooligans' who combine support for their club or national side with organized violence. Another negative effect of international sporting events upon diplomacy is to attract groups who achieve their own political objectives by disrupting occasions for international comity: terrorists. The recent attack on the Togolese football team en route to the 2010 African Cup of Nations competition in Angola is one of the more notorious examples. In practice, international sport increases international comity and reduces conflict more frequently than it exacerbates tension. The diplomacy perspective on international sport does ask the question what conditions make international sport more likely to produce comity, e.g. good diplomatic representation and communication between governments and international sporting bodies (see below), security cooperation, etc.

The results of international sporting competitions also have an impact upon diplomacy between the states of the competitors. When competitions take place in situations where external observers ascribe an overt diplomatic significance to the contest, invariably the potential significance of particular outcomes of the competition is analysed. As mentioned above, India's national cricket side toured Pakistan in 2004 to restart diplomatic relations after the 2002 crisis over terrorist attacks in Indian-administered Kashmir, which brought the two nations to the brink of potentially nuclear warfare. Political analysts agreed that the 'best' outcome would be if neither side won convincingly. The two sides played their first one-day international match in Karachi on Saturday, 13 March. India won by only five runs: 349 for 7 to Pakistan's 344 for 8 (BBC News 2004). This illustrates the broader point that scoring systems, ways of counting wins, losses and achievements more broadly, often make a significant difference in how the results of international sporting competition are perceived and thus how populations in the competing countries and elsewhere may view them as a proxy for the diplomatic relationship between the competitors.

In bilateral matches or competitions, the diplomatic impact of winning and losing can be heightened. In many games and competitions, there is a winner and a loser, or in competitions involving multiple nations, a winner and several 'also rans'. In some games, such as cricket, football/soccer and chess, a draw is possible, and in fact not infrequent. Whilst domestic publics naturally root for their home sides to win, external commentators may judge a draw to be the outcome most conducive to maintaining stable relations, as in the Fischer-Kasparov (USA-USSR) chess matches during the Cold War. In long-running competitions, such as the Ashes competition in cricket between England and Australia, 
which has been played since 1882, there is a long-term record of achievement to be measured in addition to the immediate result in a particular year, which sometimes has a mitigating effect on public perceptions of the outcome of any particular match. Between 1882 and 2011 of Ashes competition, Australia has won 123 matches, England 100 and 87 have been draws. The relatively balanced run of Ashes results is seen by the publics of both countries as a proxy for the close but competitive diplomatic relationship between the UK and Australia (Smith 2010). Many international contests, such as the World Cups of most major sports, are organized to ensure the maximum possibility of participation by the largest number of countries, which minimizes negative diplomatic fallout from a winnertake-all competition format. Most of these competitions commence with a lengthy qualifying 'round robin' competition that generates a 'league table' of results. The best teams advance to compete in the finals, which run as a single tournament. The finals begin with a group stage in which each team in the group plays all the others. The best performers from each group go forward to the final, knockout rounds of the competition. In sports involving individual competitors, such as tennis, qualifying for major international tournaments involves achieving an international ranking over time. Competitors are then 'seeded' according to relative rank by the governing body of the sport and placed in the first round of a knockout pyramid based on a formula intended to result in the highest-seeded players meeting one another in the final rounds of the tournament.

The different ways of advancing and winning in international competitions illustrate that, Westphalian fiction of sovereign diplomatic equality aside, nation states differ vastly in their size, wealth, capacities and talents. The global public develop perceptions and form opinions of nation states at least in part according to the performance of their individual competitors and national sides in international sporting competitions. Expectations for performance are not uniform: oftentimes for a small, poor or recently independent country, doing significantly better than expected in an international competition can be more important than winning an expected match for a large, sportintensive state. Merely competing in an unexpected sporting event, as when Jamaica entered a bobsleigh team in the Winter Olympics at Calgary in 1988 (subsequently memorialized in the 1993 film Cool Runnings) can win attention and accolades and, in doing so, generate the positive place branding that is a key objective of public diplomacy.

Multiple methods of measuring achievement in some international competitions facilitate recognition of accomplishment despite differences between competitors and countries. In the Olympics, a multi-sport competition in which most nations of the world participate, one recognized metric is the ability to compete at all. Some countries field Olympic teams of fewer than half a dozen competitors and enter only one or two sports. Merely to attend and represent one's country at the Olympics is perceived at home and globally as a 'win'. At the other end of the spectrum, different tallies of Olympic medal winners produce a range of metrics of national achievement: total number of medals (gold, silver and bronze), total number of golds, largest number of sports in which a country 'medals', etc. In Rugby Sevens competitions, four different trophies are awarded: cup, plate, bowl and shield, for the first through fourth place finishers respectively. Once the group stage of the competition is complete, winning and losing teams alike continue to play in a sort of repechage format that ensures that even the fourth-place finisher is the 'best' among the 'worst' finalists. This enables states with very small populations, such as Pacific island nations Niue and the Cook Islands, to win Sevens trophies alongside rugby powerhouses such as New Zealand and France.

A further complication that can arise in scoring international competition concerns sports where performances must be evaluated by a panel of judges for technical merit and, 
sometimes and even more controversially, for artistic impression. Sports ranging from diving to ice dancing, gymnastics and freestyle skiing confront the challenge of the subjectivity (and intersubjectivity) of judges, who customarily are drawn from a range of countries in an effort to avoid any national bias. Under various rules, judges' high and low scores may be disqualified to ensure that possibly biased outlier scores do not compromise overall fairness of the judging. International figure skating still suffers reputationally from a scandal at the 2002 Winter Olympics in which French judges were accused of conspiring to manipulate results. The scandal fanned anti-French sentiments in the USA at a time when bilateral relations were strained over France's opposition to US-led plans to invade Iraq. In sports that require judging, the global public's perceptions of nations' judges' professionalism as well as their competitors' fair play affect public esteem for states in a public diplomacy sense.

\section{The specialized diplomacy of international sport}

In order for an international sporting competition to take place successfully, a whole category of multi-actor diplomatic representation and communication focused on negotiating the terms of and then producing the event must have occurred already. This specialized diplomacy that international sport spawns is arguably even more significant than the effects of international sport upon diplomatic relationships. A particularly vivid example of specialized diplomacy surrounded the 2002 FIFA World Cup, which was hosted jointly by Japan and South Korea. The two governments had to negotiate with one another, their respective national football federations and FIFA to agree on viable terms for the hitherto untried co-hosting arrangement. Following FIFA's awarding of the World Cup, these actors, along with global sponsoring and media firms, had to communicate and negotiate on an ongoing basis for the seven-year period running up to and through the staging of the event (Manzenreiter 2008). This ultimately successful but challenging process depended for its success on the driving force of FIFA to make it work, which highlights the importance of international sporting bodies in the specialized diplomacy of international sport.

Each international sport or sporting event, in order to function successfully, requires an institutional structure that includes rules, norms and, most particularly, some sort of administrative body or entity to manage international interaction within the sport. Much as international governance bodies such as the United Nations and the World Trade organization administer sets of rules and norms to which their members have agreed to comply, international sporting bodies must administer the rules of the sport and general norms of fairness, including training and employing referees to arbitrate international competition. These bodies, the larger of which have tremendous power and control over assets (e.g. IOC, FIFA and the International Cricket Council [ICC]), resemble other multilateral institutions as diplomatic actors in a number of other respects. They have charters or constitutions containing a mission statement that define their objectives. They have flags and other visual symbols of their identity, which they use in a highly selfconscious effort to brand themselves and their sport (and the unity thereof). They have interests and agenda priorities to pursue.

In order to achieve their interests and pursue their objectives, international sporting bodies must themselves engage in diplomatic representation to and negotiation with governments, the regional and national organizing bodies of the sport, large global firms that sponsor competition, global media firms and global CSOs. Major subjects of negotiation include the awarding of rights to cities and countries to host major 
international sporting events, provision of adequate security for such 'mega-events', the awarding of sponsorship and broadcasting contracts and the linking of major sporting events to humanitarian and economic development objectives (Herzenberg 2010-2011; Cornelissen 2011). Sporting bodies must also communicate with the global public on an ongoing basis to promote the sport, enhance its visibility and attest to its fairness and legitimacy. Websites have become major portals for international sporting bodies to communicate about their aims and the aims of the sport. International sporting bodies increasingly proclaim the importance of their sport and competition as a global force for good. On FIFA's website, for example, FIFA describe their core mission as: 'to contribute towards building a better future for the world by using the power and popularity of football' (FIFA 2012).

All of these specialized diplomatic activities in which international sporting bodies engage require the same skills and sensitivities required of diplomatic representatives of governments or other non-state diplomatic actors, so senior managers of sporting bodies must become skilled and effective diplomats. When figures such as the late IOC President Juan Antonio Samaranch or the current FIFA head Joseph 'Sepp' Blatter or one of their senior representatives arrive in a country hoping to host an Olympiad or a World Cup competition, they are often treated as visiting heads of state or the ambassadors thereof. According to Manzenreiter (2008, 414), IOC and FIFA senior officials are granted 'semiofficial ambassador status' in the global diplomatic community. But as in diplomacy between governments, this level of respect does not come for free. Bodies that organize international sport are faced with a dual task: not only must they organize the sport, but they must also govern themselves. The reputation of these organizations plays a key role in their perceived legitimacy, which in turn has a major impact on their effectiveness in negotiating to achieve their objectives.

Allegations of corruption in international sporting bodies, and proof if found, does great harm to the credibility that they require to produce major international sporting events successfully. When allegations of bribery in the bidding process for the 2002 Winter Olympic Games, which were awarded to Salt Lake City, Utah, in the USA, were made public, a serious investigation was undertaken by the IOC. The investigation resulted in sanctions against the responsible parties and reforms to the Olympic bidding process intended to reinforce both the actual and perceived fairness and transparency of the selection mechanism (Mackay 1999). Recent allegations of corruption against senior FIFA officials with regard to the awarding of the 2018 and 2022 FIFA World Cups resulted in the resignation of FIFA Vice President Jack Warner and the withdrawal of Asian football federation chief Mohamed bin Hammam as a challenger to sitting FIFA President Joseph 'Sepp' Blatter in the 2012 FIFA presidential election (Associated Press 2011; Kelso 2011a). Blatter himself was forced to contend with calls for his own resignation by numerous national football federation officials and widespread criticism in the global media and from government officials, particularly in countries passed over in the 2018 and 2022 selection. In response, Blatter was forced to undertake a rapid public diplomacy offensive in which he promised to lead a drive to reform FIFA and the World Cup selection process himself. Yet his own loss of credibility following the Warner-bin Hammam scandal resulted in his FIFA reform proposals being taken less seriously by the range of diplomatic interlocutors to whom they were addressed (Kelso 2011b).

Likewise, all of these other types of diplomatic interlocutor must represent themselves to and negotiate with international sporting bodies and, in some cases, one another, on a regular basis. Forming an effective working coalition between several agencies in a national government, a sub-national government, in some cases a metropolitan 
government, a national sporting body and sometimes national and regional chambers of commerce that can negotiate with an international sporting body is today a required element for countries and cities hoping to secure the right to host a major event such an Olympiad, the Commonwealth Games or a World Cup of a major sport. David Black documents effectively how fractures in such a coalitions undermined and eventually resulted in the withdrawal of Halifax, Nova Scotia, Canada's bid to host the 2014 Commonwealth Games (Black 2008).

Another serious issue requiring negotiation is corruption related to match fixing in national sporting bodies. Corruption can persist for lengthy periods of time because it is less visible internationally, processes for remedying it are usually conducted at the national level and remedies are much more subject to national politics and culture. However, over time national-level corruption affects international competition in the sport by calling into question the eligibility and legitimacy of that nation's competitors and may require intervention by the sport's international governing body. The troubles in recent years of the South African and Pakistani national cricket federations are cases in point (ICC 2001). In the most infamous case to date, South African Test captain and cricket star Hansie Cronjie forfeited his captaincy after confessing to match fixing in 2000, for which he was paid $£ 65,000$ in bribes. In November 2011, three Pakistani cricketers on Pakistan’s national side, including Test captain Salman Butt and a Londson sports agent, were convicted in a UK court of match fixing at international matches and sentenced to jail terms. The players also received five-year playing bans from the ICC (Turbervill 2010; The Guardian 2012).

The fact that international sporting competition takes place under different formats further complicates the specialized diplomacy of international sport. The various ways of organizing competition in different sports each mandate that the requisite governing body for the sport possess particular diplomatic skill sets. This variation of competition formats produces a taxonomy of international sporting bodies as diplomatic actors, the variation in which resembles that of governments: large to small, strong to weak. There are four principal formats for international sporting competition. The first, team sports in which national sides compete against one another, requires a strong world governing body for the sport. Such sporting federations must have the institutional capacity to engage in diplomatic relationships with national governing bodies, governments, global corporate sponsors and media firms, and CSOs. Football/soccer (FIFA), cricket (ICC), rugby (International Rugby Board [IRB]) and basketball (Fédération Internationale de Basketball Amateur) are some examples.

The second format includes individual competition sports such as tennis and golf. In this category, tennis players and golfers compete internationally in national teams in events such as tennis' Davis Cup and golf's Ryder Cup. In those cases, the governing bodies for the sports, e.g. the International Tennis Federation and the International Golf Federation, must function as diplomatic actors as much as the team sport governing bodies do. However, in these sports, individual competitors also enter major international competitions as individuals, representing themselves and their countries as individuals. Events such as the British Open and US Open in Golf, Wimbledon and Roland Garros in tennis, are organized by the respective national sporting bodies, e.g. the US Professional Golfers Association and the US Tennis Association. This gives the international sporting body less leverage over individual players than in the case of bodies representing team sports and thus also places the international sporting federation in a weaker position relative to governments and national sporting federations when issues arise that require negotiation. Even in terms of public diplomacy and brand identity, individual tennis 
players and golfers and the major tournaments in which they compete are much better known globally than the international sporting body to which they belong.

A third format is team sports in which teams made up of competitors of different nationalities are sponsored and funded directly by global firms and operated as a quasibusiness venture. Motor sports (Formula One, World Superbike Championship) and cycling are primary examples. Competitors represent their countries in an iconic sense but do not compete on behalf of them in any formal way. In these cases, the international governing body of the sport has even less power with respect to global sponsor and media firms or to governments. For example, decisions on where to locate Formula One races are made largely by representatives of the major sponsored teams, their sponsors and government officials of prospective host countries. Hence these types of sporting bodies must become very skilled at dealing with sponsoring firms if they hope to maintain any real influence over competition in the sport. When crises arise that require negotiation, such as the ongoing doping scandal in cycling, governments may become involved, but are more likely to deal directly with the teams and their sponsors unless the relevant sporting body can make itself relevant and necessary to the resolution of the crisis.

The fourth format is the Olympics, in which the IOC, a huge multinational, multi-sport organization, wields enormous power with respect to all the other actors with which it must engage in communication and representation. The IOC's primary diplomatic interlocutors are national governments, national Olympic committees in the participating countries, major sponsoring and media firms, and CSOs. The process of producing a successful Olympiad, summer or winter, is enormously complicated and costly, extending for the best part of a decade from the competition between cities to win a bid to host the Games to the marketing of a successful event to the world after the fact. National Olympic committees, sovereign entities but affiliated with the IOC, must communicate and negotiate with the IOC, on the one hand, and all of the national sporting federations whose members compete in Olympic sports, on the other, to create, maintain and promulgate the rules of competition, enforce the rules at national level and ensure that national Olympic teams meet relevant competitive standards.

Another specific aspect of the specialized diplomacy of international sport concerns the diplomatic accreditation or recognition of competitors in a sport. This issue is important because only when a representative is accredited can the substantive work of diplomatic representation begin, yet decisions about whom to recognize and not recognize are often themselves diplomatic matters and topics for negotiation (Constantinou 1996). These decisions are by their nature political to the core and are often highly contentious and contested. Each sport's international governing body must decide which national sporting federations to recognize - to accept as members. This is contentious because it evokes every debate about sovereignty in the international system that plagues diplomats of governments and other multilateral organizations. One of the most obvious cases is the status of sporting federations of the People's Republic of China and the Republic of China on Taiwan. The Beijing government objects to Taiwan competitors competing at international events under any name that implies the sovereignty of Taiwan or Taiwan's claim to sovereignty over China. Fortunately, in most cases, compromises have been negotiated that permit both polities to field teams. In the case of the Olympics, officials of Beijing and Taipei reached an agreement facilitated by the diplomatic offices of the IOC under which Taiwanese competitors compete under the name 'Chinese Taipei' and the five-ringed Olympic flag (The China Post 2008).

In a darker example, imperial Japan during its period of East Asian domination compelled Korean athletes to compete on behalf of Japan in the 1936 Berlin Olympics 
(Manzenreiter 2008, 416). Even when sovereign borders change consensually, diplomatic problems of accreditation and representation concerning sporting competition arise that international sporting bodies must address if they are to meet global expectations that all competitors meeting their standards of excellence be permitted to compete. Following the voluntary dissolution of the Soviet Union at the end of 1991, the national sporting federations of the successor republics were not yet sufficiently organized to compete in the summer 1992 Barcelona Olympiad. Hence the IOC negotiated an arrangement under which the former Soviet republics would compete together for a last time under the moniker 'Equipe Unifiée' ('Unified Team'), again under the Olympic flag.

Each international sporting organization either sets its own rules for competitors' eligibility to compete for particular states or else grants that power to national sporting federations. This issue can become highly contentious, as it raises issues of fairness in competition between nations and because it unpicks many of the conventional constructions of identity politics that underlie much of diplomacy. Competitors frequently have parents from different countries, are descended from family of a different country from that of their citizenship, reside and train in a different country from their 'home' country or migrate (for purposes of training or for other reasons, including political or economic asylum) from one country to another. Many sporting federations in countries that are small, poor or lack investment in sport adopt very liberal eligibility policies designed to entice diaspora competitors to compete on behalf of their ancestral nation. Sometimes this places competitors in the fortunate position of having multiple eligibility and being able to choose the state for which they will compete (Maguire 2008). But in order for international competition to proceed successfully, national decisions on eligibility must be perceived by the international sporting federation and other competing nations as legitimate. Eligibility has even been contested over criteria such as gender, as in recent challenges to the eligibility of South African track and field star Caster Semenya to compete as a female athlete (Daily Mail 2011).

Another issue in the specialized diplomacy of international sport related to accreditation and recognition concerns cases when national sporting federations that are accredited to compete internationally do not coincide with sovereign states and recognized international borders. This situation occurs primarily for historical reasons, for example in football/soccer and rugby the 'national' sides of England, Scotland and Wales are recognized as competitors in their own right by FIFA, the IRB and the IOC. Only on limited occasions do competitors in these sports compete as a UK team, e.g. the 'British Lions' in rugby. In Ireland, designations are even more complicated, as competitors from Northern Ireland, a part of the UK, sometimes compete as Northern Ireland but in many sports are also eligible (as residents of the Irish island) to compete for the Irish Republic. In lacrosse, the Iroquois Confederation, an indigenous aboriginal population of North America whose historical territory spans areas of the USA and Canada, is recognized by the Federation of International Lacrosse as a national sporting federation, primarily because their people invented the game. This would normally be unproblematic, but when the Iroquois national lacrosse team travelled to the UK for the 2010 Lacrosse World Cup on passports issued by Iroquois Confederation tribal authorities, they were denied entry into the UK. Although the US government treated them as valid exit documents, and their validity was also acknowledged by the Canadian, Japanese and Australian governments, UK officials claimed the passports did not have the required electronic security coding to ensure their authenticity. The incident provoked a full-blown diplomatic contretemps over rights of indigenous peoples involving several governments, sporting federations and the Iroquois tribal council (MacAskill 2010). 
A more complex question of recognition and accreditation arises when a single international sporting body is not generally acknowledged by individual competitors and national federations to be the authoritative organizer of international competition in that sport. These situations resemble cases in state-state diplomacy in which governments join overlapping and in a sense 'rival' regional trade groupings so as to reap benefits from being a member of each that they could not obtain from participating in only one. South Africa, for example, is a member of the African Union, the Southern African Development Community, the Southern African Customs Union and the India-Brazil-South Africa grouping. In these relatively uncommon situations in the diplomacy of sport, rival international sporting bodies for a single sport each organize competitions, which motivate competitors to seek to win championships hosted by all the relevant rival bodies in order to be generally recognized as a world champion. Boxing has faced the most infamous of these situations, with at times up to six rival bodies claiming to be the official international organization for the sport.

\section{Conclusion}

In a globalized world, international sport continues to grow in terms of quantity of sports, number of events, number of participating countries, number of participants, number of fans and spectators, and corporate sponsorship. Understanding the relationship between international sport and diplomacy plays an important part in understanding the impact of international sport on society in the broadest sense. But perhaps more significantly, coming to understand the ways that international sport is used as an instrument of diplomacy by governments can generate important prescriptive conclusions that can enable governments to use sport for diplomatic purposes more effectively. Officials in foreign ministries, for example, might develop a clearer sense of the conditions under which a diplomatic initiative involving sport might be most likely to be successful, as opposed to a different type of initiative (e.g. another form of cultural diplomacy, a secret negotiation, etc.). Likewise, coming to understand the specialized diplomacy of international sport can generate prescriptions that can enable international sporting organizations to fulfil their objectives of facilitating the most successful international sporting competitions possible, with all of the possibilities for Chehabi's people-to-people diplomacy that such competitions bring. For example, organizations like FIFA and the IOC might be able to learn from the best-practice standards of representation and communication of other types of international organizations that function as diplomatic actors, such as NATO and the World Trade Organization. The reputational damage to FIFA resulting from the recent spate of scandals involving their selection process for World Cup venues indicates how poorly FIFA does public diplomacy. Tapping into public diplomacy research such as Fitzpatrick's (2007) work on the 'relationship management' approach to public diplomacy could generate tangible benefits to organizations such as FIFA. The foregoing taxonomical survey of the relationship between diplomacy and international sport is intended to serve as a template for situating further research in this hitherto under-studied area.

\section{Notes}

1. The genesis of this section of the paper came from Stuart Murray's presentation 'SportsDiplomacy: A Hybrid of Two Halves' at 'The International Symposium on Cultural Diplomacy', Berlin, 11-15 May 2011. 
2. For example, multinational corporations such as Microsoft, Philips, Sony, Mitsubishi and General Motors all intervene in international affairs to protect and promote their interests and values. To do so means to use uses diplomacy as a means to ensure they met their responsibilities beyond making computer software. Microsoft's Critical Infrastructure Partner Program, for example, fosters partnership between national governments based on mutual trust, common goals and collaboration; and the software giant also has Disaster \& Humanitarian Response plans, built on diplomatic partnerships with the Department of State, the American Red Cross and the UN High Commissioner for Refugees.

3. After a long practice session, Cowan realized he had missed his team bus. In true sporting spirit, a Chinese player waved him to get on the Chinese team bus. Cowan soon began talking to the Chinese players through an interpreter when Zhuang Zedong, to his surprise, presented him with a silk portrait of the Huangshan mountains. By the time they were due to get off the bus, a crowd of journalists had assembled to capture the rare sight of an American and Communist Chinese athlete together. At a later meeting, Cowan reciprocated by giving Zhuang a T-shirt with a peace emblem and the words 'Let It Be' inscribed.

4. Thanks to Caitlin Byrne of Bond University for help with this definition.

5. SportsUnited is an international sports programming initiative designed to help start a dialogue at the grassroots level with non-elite boys and girls, aged 7-17. The programmes aid youth in discovering how success in athletics can be translated into the development of life skills and achievement in the classroom. Foreign participants are given an opportunity to establish links with US sports professionals and exposure to American life and culture. Americans learn about foreign cultures and the challenges young people from overseas face today.

6. In the build-up to the 1996 European Soccer Championships, several English footballers were photographed in a Hong Kong nightclub on a drunken night out. A photograph showing stars Teddy Sherringham and Steve McManaman pouring alcohol into Paul Gascoigne's mouth while sitting in the infamous 'Dentist's Chair' caused a great amount of public embarrassment for the English football association and the British Government. To top it off, the team caused thousands of pounds worth of damage to a Cathay Pacific first-class flight cabin. Here, the British seem particularly adept: John Jeffrey and Dean Richards, respective Scottish and English rugby legends, were each banned from competition after 'playing rugby' with the ancient and fragile Calcutta Cup. After Scotland lost the match 9-6, and after a fair amount of Whisky and Drambuie were consumed, Jeffrey and Richards had an impromptu game with the Cup on Princes Street, damaging it and their countries' reputations significantly.

7. Sir Ernest Satow quoted in Bull $(1977,175)$.

8. During the ancient Olympics, the word for competition was agon, where the English word agony is derived from; similarly, the etymology of the words athlete and athletics comes from the Greek word athlos, a contest taking place in a stadium or on a battlefield. Vide Sweet (1987).

9. As an example, consider the World Cup, which 'the victors, like officiating priests, lift triumphantly to the heavens on the day of victory. No spiritual or intellectual message is conveyed, no hope for humanity, no promise for the human condition comes from this ceremony, where only the law of the strongest are celebrated' (Redeker 2008, 495).

10. There are other issues: any diplomatic meeting generated by a sporting event is bound to be too short, or that possibilities for negotiation are limited because the heads of state outline their objectives before the meeting has taken place (and to renege will be viewed as a weakness by their electorate), or who foots the exorbitant cost of securing the venue?

11. Vide section below on international-sport-as-diplomacy on the specialized diplomacy required to make international competition possible.

\section{References}

Allison, L. 1993. The Changing Politics of Sport. Manchester: Manchester University Press.

Associated Press. 2011. "Scandal Spreads to 2022 Cup Bid." ESPN, 30 May. Accessed February 8, 2012. http://espn.go.com/sports/soccer/news/_id/6606997/fifa-bribery-scandal-spreads-qatarworld-cup-bid

Auswärtiges Amt. 2010. "People on the Move: Overcoming Borders." 19 April. Accessed February 11, 2012. http://www.auswaertiges-amt.de/EN/Aussenpolitik/KulturDialog/Initiativen/Sport2010Konzept_node.html 
BBC News. 2004. "India Win Thriller.” 13 March. http://news.bbc.co.uk/sport1/hi/cricket/other_ international/3507532.stm

Berridge, G. R. 2002. Diplomacy: Theory and Practice. London: Palgrave.

Black, David. 2008. "Dreaming Big: The Pursuit of 'Second Order' Games as a Strategic Response to Globalization." Sport in Society 11 (4, July): 467-480.

Bull, Hedley. 1977. The Anarchical Society: A Study of Order in World Politics. New York: Columbia University Press.

Cain, Jim. 2009. "Hoop Diplomacy." Paper presented at the 2nd Hague Conference on Diplomacy, The Hague, The Netherlands, 18-20 June.

Chehabi, H. E. 2001. "Sport Diplomacy Between the United States and Iran." Diplomacy \& Statecraft 12 (1, March): 89-106.

Cohen, Raymond. 1998. "Putting Diplomatic Studies on the Map." In Diplomatic Studies Program Newsletter. Leicester: Centre for the Study of Diplomacy.

Constantinou, Costas M. 1996. On the Way to Diplomacy. Minneapolis: University of Minnesota Press.

Cornelissen, Scarlett. 2011. "Mega Event Securitisation in a Third World Setting: Glocal Processes and Ramifications During the 2010 FIFA World Cup." Urban Studies 48 (15, November): $3221-3240$.

Daily Mail. 2011. "IAAF Introduce New Gender Rules for Female Athletes Following Semenya Affair." 12 April. Accessed February 16, 2012. http://www.dailymail.co.uk/sport/othersports/ article-1376059/Caster-Semenya-affair-prompts-IAAF-introduce-new-gender-rulesfemale-athletes.html

Defrance, Jacques, and Jean Marc Chamot. 2008. "The Voice of Sport: Expressing a Foreign Policy Through Silent Cultural Action: The Case of French Foreign Policy After the Second World War." Sport in Society 11 (4): 395-413.

Der Derian, James. 1987. On Diplomacy: A Genealogy of Western Estrangement. Oxford: Blackwell.

Farr, Malcolm. 2010. “The True Story of Why John Howard is a Pie-Chucker.” The Punch, 2 July. Accessed January 5, 2012. http://www.thepunch.com.au/articles/the-true-story-of-why-johnhoward-is-a-pie-chucker/

FIFA. 2012. "The Organisation, Mission and Statutes." Accessed February 1. http://www.fifa.com/ aboutfifa/organisation/mission.html

Fischer, Norman. 2002. "Competitive Sport's Imitation of War: Imaging the Completeness of Virtue." Journal of the Philosophy of Sport XXIX: 16-37.

Fitzpatrick, Kathy. 2007. "Advancing the New Public Diplomacy: A Public Relations Perspective." The Hague Journal of Diplomacy 2 (3): 187-211.

Herzenberg, Colette Schulz, ed. 2010-2011. Player and Referee: Conflicting Interests and the 2010 FIFA World Cup (Monograph 169). Pretoria: Institute for Strategic Studies.

Hocking, Brian. 2006. "Multistakeholder Diplomacy: Forms, Functions and Frustrations." In Multistakeholder Diplomacy: Challenges and Opportunities, edited by Jovan Kurbalija, and Valentin Katrandjiev, 13-33. Malta: Diplo Foundation.

Huang, Rune-Wen. 2008, February 7. "Diplomacy in the Sports Arena." Accessed March 1, 2012. http://uschina.usc.edu/fulllist@usct?author_Rune-Wen\%20Huang_71.aspx

Hugh, Lee M. 1998. "The Ancient Olympic Games: Origin, Evolution and Revolution.” The Classical Bulletin 74 (2): 129-141.

International Cricket Council. 2001. "Report on Corruption in International Cricket." London, April. Accessed February 8, 2012. http://icc-cricket.yahoo.net/anti_corruption/condon-report.php

International Olympic Truce Centre. 2012. "Imagine Peace." Accessed March 23. www.olympictruce. org/Pages/History.aspx?sub=AncientGreece

Jackson, Steven J., and Stephen Haigh. 2008. "Between and Beyond Politics: Sport and Foreign Policy in a Globalizing World." Sport in Society 11 (4): 349-358.

Keech, Marc, and Barrie Houlihan. 1999. "Sport and the End of Apartheid." The Round Table: The Commonwealth Journal of International Affairs 88 (349): 109-121.

Kelso, Paul. 2011a. "Former FIFA Vice-President Jack Warner is Caught on Tape Offering 'Gifts' of $£ 25,000$ to Caribbean Delegates." Daily Telegraph, London, 12 October. Accessed February 8, 2012. http://www.telegraph.co.uk/sport/football/international/8820948/Former-Fifa-vicepresident-Jack-Warner-is-caught-on-tape-offering-gifts-of-25000-to-Caribbean-delegates.html 
Kelso, Paul. 2011b. “Sepp Blatter's Fifa Reform Committee Hit by Fans' Group Boycott.” Daily Telegraph, 16 December. Accessed March 23, 2012. www.telegraph.co.uk/sport/football/ international/8961622/Sepp-Blatters-Fifa-reform-committee-hit-by-fans-group-boycott.html Kuper, Simon. 2010. Soccer Against the Enemy: How the World's Most Popular Sports Starts and Fuels Revolutions and Keeps Dictators in Power. New York: Nation Books.

Kyle, Doug. 1983. "Directions of Ancient Sport History." Journal of Sports History 10 (1): 7-34.

Leira, Halvard, and Iver Neumann. 2008. "The Emergence and Practices of the Oslo Diplomatic Corps." In The Diplomatic Corps as an Institution of International Society, edited by Paul Sharp, and Geoffrey Wiseman, 83-102. London: Palgrave Macmillan.

MacAskill, Ewen. 2010. "Iroquois Lacrosse Team Caught in a Cleft Stick Over Passports." The Guardian, 13 July. Accessed March 23, 2012. http://www.guardian.co.uk/world/2010/ jul/13/iroquois-lacrosse-passport-world-cup

Mackay, Duncan. 1999. "Long Live the King, Says IOC, After Six Voted Out." The Guardian, 18 March. Accessed March 23, 2012. www.guardian.co.uk/Olympic_scandal/Story/0,209573,00. html

Maguire, Joseph. 2008. “'Real Politic' or 'Ethically Based': Sport, Globalization, Migration and Nation-State Policies." Sport in Society 11 (4, July): 443-458.

Manzenreiter, Wolfram. 2008. "Football Diplomacy, Post-Colonialism and Japan's Quest for Normal State Status." Sport in Society 11 (4): 414-428.

Mattingly, Garret. 1938. "An Early Nonaggression Pact." Journal of Modern History 10 (1): 1-30. Modelski, George. 1972. Principles of World Politics. New York: Free Press.

Ramsay, Allan. 2006. “Is Diplomacy Dead?" Contemporary Review 288 (1682, Autumn): 273-289.

Redeker, Robert. 2008. "Sport as an Opiate of International Relations: The Myth and Illusion of Sport as a Tool of Foreign Diplomacy." Sport in Society 11 (4): 494-500.

Rupert, James. 2011. "Cricket Diplomacy May Smooth Tension Between India, Pakistan." Bloomberg, 28 March. Accessed April 28, 2011. http://www.bloomberg.com/news/2011-03-28/ cricket-diplomacy-at-world-cup-may-smooth-tension-between-india-pakistan.html

Scrambler, Graham. 2005. Sport and Society: History, Power and Culture. Sydney: McGraw Hill Education.

Smith, Stephen, M. P. 2010. "Celebration of 100 Years of Diplomacy with the UK (Press release)." 18 February. Accessed March 23, 2012. http://www.foreignminister.gov.au/releases/ 2010/fa-s100219.html

Sugden, John, and Alan Tomlinson. 1998. FIFA and the Contest for World Football: Who Rules the Peoples' Game? Cambridge: Polity Press.

Sweet, Waldo E. 1987. Sport and Recreation in Ancient Greece. Oxford: Oxford University Press.

The China Post. 2008. "President Ma Cheers on Taiwan's Olympic Athletes." 31 July. Accessed March 23, 2012. www.chinapost.com.tw/taiwan/national/nationalnews/2008/07/31/168019/ President-Ma.htm

The Guardian. 2012. "Spot-Fixer Mohammad Amir Released After Three Months of Sentence." 1 February. Accessed February 16, 2012. http://www.guardian.co.uk/sport/2012/feb/01/ mohammad-amir-released-pakistan

Toohey, Kristine. 2008. "Terrorism, Sport and Public Policy in the Risk Society." Sport in Society 11 (4): 429-442.

Turbervill, Huw. 2010. "How Hansie Cronje Became Most Infamous Villain in Cricket's Fixing Scandals." The Telegraph, 26 May, http://www.telegraph.co.uk/sport/cricket/international/ 7765224/How-Hansie-Cronje-became-most-infamous-villain-in-crickets-fixing-scandals.html

Walters, Caroline. 2007. "Sports Diplomacy is the New Comeback Kid." 3 August. Accessed April 29, 2011. http://uscpublicdiplomacy.org/index.php/newswire/cpdblog_detail/070803_sports_ diplomacy_is_the_new_comeback_kid/

Wight, Martin, and Herbert Butterfield. 1966. Diplomatic Investigations. Cambridge, MA: Harvard University Press.

Wiseman, Geoffrey. 1999. “Polylateralism' and New Modes of Global Dialogue.” Leicester Diplomatic Studies Programme Discussion Papers No. 59. 